\title{
Absenteeism amongst health workers - developing a typology to support empiric work in low-income countries and characterizing reported associations
}

\author{
Alice Belita ${ }^{1 *}$, Patrick Mbindyo ${ }^{1}$ and Mike English ${ }^{1,2}$
}

\begin{abstract}
The contribution of inadequate health worker numbers and emigration have been highlighted in the international literature, but relatively little attention has been paid to absenteeism as a factor that undermines health-care delivery in low income countries. We therefore aimed to review the literature on absenteeism from a health system manager's perspective to inform needed work on this topic. Specifically, we aimed to develop a typology of definitions that might be useful to classify different forms of absenteeism and identify factors associated with absenteeism. Sixty-nine studies were reviewed, only four were from sub-Saharan Africa where the human resources for health crisis is most acute. Forms of absenteeism studied and methods used vary widely. No previous attempt to develop an overarching approach to classifying forms of absenteeism was identified. A typology based on key characteristics is proposed to fill this gap and considers absenteeism as defined by two key attributes, whether it is: planned/unplanned, and voluntary/involuntary. Factors reported to influence rates of absenteeism may be broadly classified into three thematic categories: workplace and content, personal and organizational and cultural factors. The literature presents an inconsistent picture of the effects of specific factors within these themes perhaps related to true contextual differences or inconsistent definitions of absenteeism.
\end{abstract}

Keywords: Absenteeism, Workforce, Sickleave

\section{Background}

There is a human resources for health crisis in sub-Saharan Africa [1-4]. The health worker density in most subSaharan countries is well below the WHO recommended minimum of 2.5 health workers per 1000 population [1,5] while the burden of disease is high [1]. One consequence of low health worker density is relatively poor health outcomes of the population [6,7]. Health worker availability is undermined by the hiring freezes present in some countries in sub-Saharan Africa [8-10], and 'push' and 'pull' factors promoting emigration from low-income countries (LICs) to high-income countries (HICs) [11,12]. Similar factors also create an uneven domestic distribution of health workers, which especially affects rural areas [13] and may promote

\footnotetext{
*Correspondence: belitaus@yahoo.com

${ }^{1}$ Kenya Medical Research Institute -Wellcome Trust Research Programme, Kenyatta National Hospital, Hospital Road, Nairobi 00100, Kenya

Full list of author information is available at the end of the article
}

moonlighting and absenteeism, among other problems $[7,14,15]$. However, relatively little attention appears to have been paid to absenteeism as a cause of poor access to health-care services in low-income countries.

We therefore aimed to review the literature on absenteeism to inform potential work on this topic in a lowincome setting. Specifically, we aimed to develop a typology of absenteeism definitions and identify factors reported to influence absenteeism among health workers.

\section{Methods}

Although our primary interest was absenteeism in low income countries an initial screen of the literature revealed very few studies specific to these settings. We therefore included in our search work from all settings. Potential articles for inclusion published in English between January 1982 and May 2012 were identified through searches of: PubMed, Web of Science, CINHAL

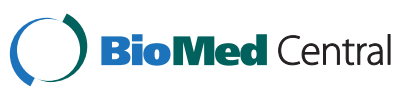


and The Cochrane Library. The search terms used were 'absenteeism' and 'health workers'; their respective $\mathrm{MeSH}$ terms were also incorporated in the search. No active search of the grey literature was undertaken after initial searches yielded a substantial number of peerreviewed articles. Additional articles were however sought by screening the reference lists of identified studies and reviews.

For the purposes of this review, we took a health system manager's perspective. Thus we did not specifically seek to explore deeper psychological or social aspects of absenteeism. Nor did we aim to examine it from an economic perspective. The framework or 'lens' though which we explored the literature aimed to uncover how absenteeism has been defined, usually for the purposes of quantification at some level of the health system e.g. within a facility, a region or a profession. Additionally, we sought to elucidate characteristics of the workforce likely to be familiar to managers that have been associated with absenteeism. We acknowledge that such characterization may not explain why health workers are absent. Alternative theoretical frameworks might be needed for such explorations. However, we reasoned that providing both a typology of absenteeism and a description of characteristics associated with it would be a good starting point for developing better informed quantitative and qualitative work in this area in the future.

Eligible studies and reviews were those that reported data on definitions and determinants of, or associations with, absenteeism among health workers. Studies of multiple cadres of hospital staff (e.g. administrative, cleaning staff) were included if they also included doctors and nurses. Article selection was performed by one reviewer who screened through the titles and abstracts and identified and selected studies based on the pre-defined study eligibility criteria. Where there was uncertainty over inclusion of a study, a second investigator was consulted and a consensus decision reached. Key aspects of all included studies, such as population studied, methods, etc., were documented in a standard format to facilitate later summary and synthesis (see Additional file 1).

After abstracting data on each manuscript we assigned the definition(s) of absenteeism employed by authors into initial groups based on similarities allowing, where necessary, reported definition(s) to be assigned to more than one group. In an iterative process thematic groupings that would capture all definitions were developed with the aim of providing a relatively parsimonious classification system and one that captured notions of expected or approved absence on the part of an organization and individual volition. In a similar way, factors reported to be associated with absenteeism were first identified within individual studies, then grouped and then assigned to thematic categories.

\section{Results}

A total of 3096 studies were identified in initial searches of all the databases. After reading through the titles and abstracts, 107 studies were further screened based on the full text with 63 studies retained for inclusion in the review. An additional six studies were identified through screening of the references of included studies. This process is summarized in Figure 1.

Included studies focused on nurses $(\mathrm{n}=36)$, all hospital workers including administrative and cleaning staff $(\mathrm{n}=25)$, physicians $(\mathrm{n}=1)$, radiographers $(\mathrm{n}=1)$, dentists $(n=1)$ and combined nurses and physicians $(n=5)$. The predominant study designs were surveys based on either retrospective or prospective analysis of absenteeism data obtained from administrative records. Other study designs used were retrospective and prospective cohort studies or studies based on interviews, focus group discussions, case control analysis or literature reviews. The majority of studies available were from HICs. Of the seven studies from low- and middle-income countries (LMICs) relevant to this review, four were conducted in Africa.

\section{Definitions of absenteeism}

Definitions of absenteeism were reported in most of the articles reviewed. Some definitions were narrow and characterized absence by specific health conditions, such as knee and back pain [16-18], or stress [19], etc. Other definitions were broad and studied absence in general, typically including absence due to illness and other causes [20-22]. Although actual definitions varied, a typological framework could be established using the following classifications of absence: planned or unplanned, voluntary or involuntary as illustrated in Table 1 . Typically such classifications are, however, based on health worker reports of the reason for absence, the veracity of which is often not determined [23].

The typology outlined draws on ideas presented across the reviewed literature. Beil-Hildebrand [23] established that nurse absence can be divided into planned and unplanned absence. Planned absence occurs when both the employee and employer are aware that the employee will not be coming to work and hence are able to plan in light of that awareness. Different examples of planned absence that fit under this definition have been studied [22,24-27]. Unplanned absence, on the other hand, occurs when an employee does not go to work and the employer actually expects him/her to be at work [23]. Sickness absence is the most common form of such absence studied (for examples see [28] and [16,29-32]).

Perhaps more subjectively, absence may occur for reasons officially allowed or not allowed as per the organization's policies. Sanctioned absence might entail different forms of allowed time off such as annual, maternity [26], 


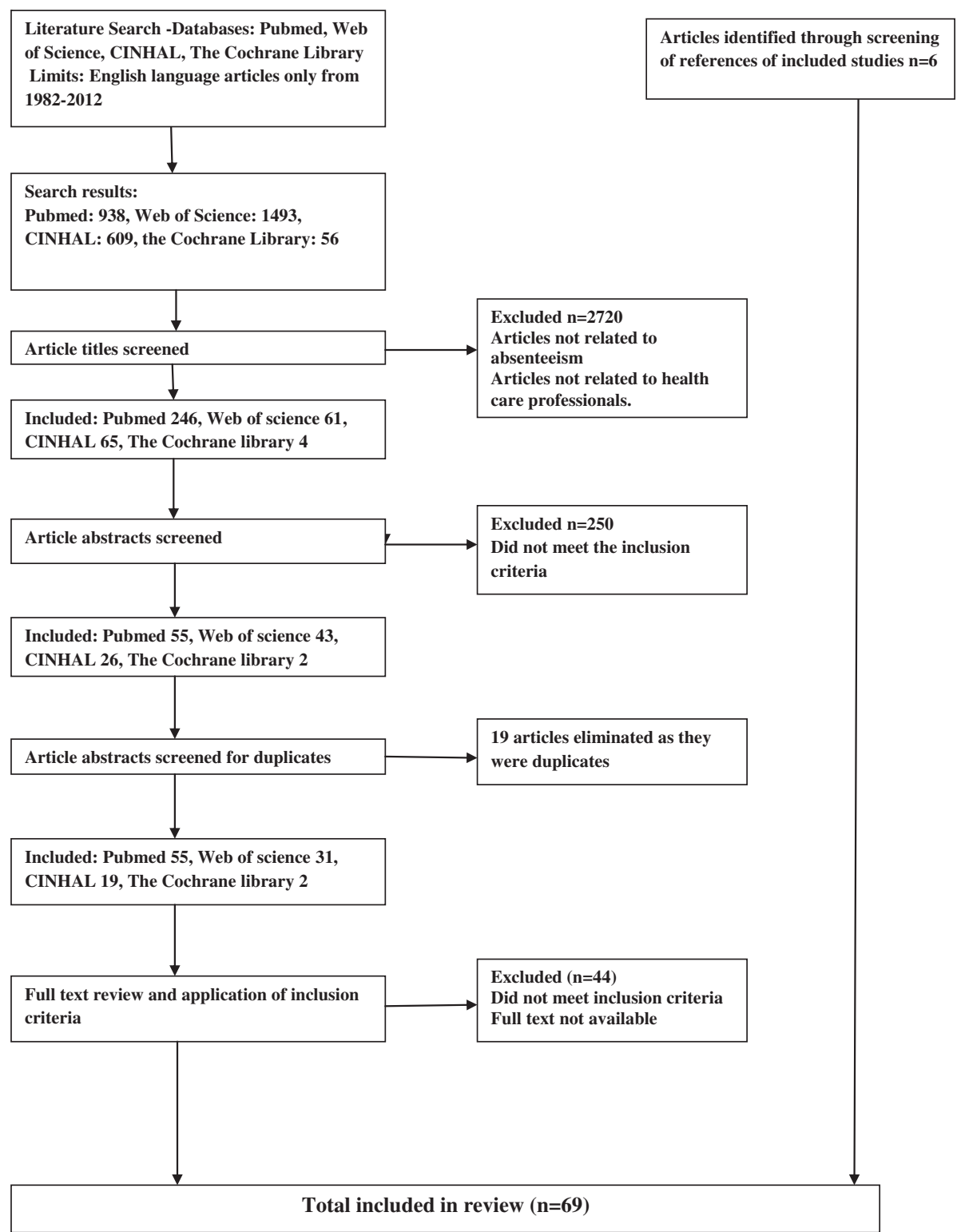

Figure 1 Flowchart of study identification and inclusion.

Table 1 A typological framework for defining absenteeism with examples of the different forms of absenteeism

\begin{tabular}{|c|c|c|}
\hline & Planned & Unplanned \\
\hline \multirow{2}{*}{ Voluntary } & $\begin{array}{l}\text { Statutory absence (annual/ vacation, study, maternity, off-duty leave), } \\
\text { training, workshops, conferences }[22,24-26]\end{array}$ & $\begin{array}{l}\text { Sickness absence to attend to personal matters as they arise } \\
\text { but reported as minor illness, often short-term self-certified } \\
{[26,35]}\end{array}$ \\
\hline & & $\begin{array}{l}\text { Failing to report to work and not giving a valid and } \\
\text { acceptable reason for one's absence (e.g. moonlighting) } \\
\text { [26,35] }\end{array}$ \\
\hline & Long-term sickness e.g. $\geq 90$ days in Scandinavian countries [27] & $\begin{array}{l}\text { Transport problem, taking care of a sick child/relative, } \\
\text { personal injury, sickness that is medicallycertified [52] }\end{array}$ \\
\hline Involuntary & $\begin{array}{l}\text { Absence caused by social obligation rather than for personal interest/ } \\
\text { benefit e.g. attendance at pre-specified event such as a political or } \\
\text { community meeting. In such cases, a different allowable reason for } \\
\text { absence may be provided to the employer in order to get time off [35] }\end{array}$ & \\
\hline
\end{tabular}


or sick leave, workshop or seminar attendance [22], or approved compassionate leave to take care of sick relatives [33]. Unsanctioned absence might involve health workers not coming to work and either not seeking or not obtaining official approval for such absence. In their study to establish the effects of organizational changes in health facilities in Costa Rica, Garcia-Prado and Chawla [34] examined absence of this type that was either unjustifiable or unexplained. Gaudine and Gregory [35] in their study used questionnaires and asked nurses to report how manydays they were away due to sickness, stress or to attend to family and personal matters. They regarded nonsickness absence as forms of 'unsanctioned absence' [35]. However, further subclassification of absence into sanctioned or unsanctioned forms may not always be clear and at present this categorization is not formally included in the proposed typology.

Absenteeism can also be classified as involuntary absence occurring for reasons beyond the employees' control and voluntary absence occurring when the employee makes the decision not to go to work [36]. It has been acknowledged that differentiating between voluntary and involuntary absence can also be difficult. However, assessment of frequency and duration of absences/sickdays has been used to distinguish between the two. High frequency of absence has consistently been regarded as a reliable measure of voluntary absence [36]. It has further been suggested that unplanned absence is often shortterm and sometimes voluntary [23]. Borda and Norman [37] in their study of nurses in Malta considered oneday or two-day absence frequency as a measure of 'avoidable' absence and related to job satisfaction, which was of concern in their study. Voluntary absence can also be planned as in the case of maternity [26] and annual [24] leaves.

It is clear that absence, even with availability of attendance records, is not always easily defined or measured. In LICs, attendance records may not be easily available [34] and may lack the required data or detail. Use of self-reported absence is often therefore demanded [38] but may be subject to bias. Determining the actual nature of the absence is thus challenging. For these reasons, if self-reported absence is used as an approach, it may be useful to explore real examples of absence and classify these posthoc. The typology presented could then be used to help classify forms of absence and their relative importance.

\section{What influences absenteeism? A system perspective}

Different factors were reported to influence health workers' absence. Broadly, these factors fitted into three thematic categories; workplace/content, personal and organizational/cultural factors. They are discussed in detail below.

\section{Workplace factors}

\section{Employment sector}

Absenteeism has been reported to be common in the public sector in high- and low-resource settings. GarciaPrado and Chawla [34] in an evaluation of reforms in the Costa Rica health sector noted that absenteeism is rampant in public organizations, although it is often not addressed in policy frameworks in the health systems of LICs [21,34]. Garcia-Prado and Chawla attribute absenteeism in public institutions to the fact that employees get their salary irrespective of performance [34]. This phenomenon has also been observed in HICs as reported by Johnson et al. [39] in the UK and other developed nations [40].

\section{Size of an organization}

The size of an organization has been said to influence absenteeism [41]. The argument being that big organizations have less group cohesiveness, greater bureaucracy and that individual efforts go unnoticed [34]. GarciaPrado and Chawla's work in Costa Rica [34] evaluating the impact of changes in reimbursement methods and organizational reforms on absenteeism found that absenteeism generally increased, and more so in big hospitals than small hospitals. In Kenya, Muthama et al. [42] reported that health workers in district and subdistrict hospitals were more absent than those in health centres and dispensaries.

\section{Facility location}

The location of the health facility, i.e. whether rural or urban and also in relation to where the health workers live has been reported to influence the absence rate of the health workers. Muthama et al. [42] hypothesized that absenteeism would be greater in rural areas linked to irregular transport and health workers needing to travel long distances to access banks and other facilities, factors associated with absenteeism in Nigeria [38]. However, they found that facilities in urban areas had higher absenteeism [42]. In Bangladesh and Kenya, health workers that lived in the same town or village as the health centre they worked in were less absent compared to those that lived away from their place of work $[21,42]$.

\section{Work content factors Workload}

Heavy workload has been identified as a reason for both short- and long-term sickness absence. This may encompass means to escape this heavy workload or to recover from illnesses caused by managing the heavy workload [43-46]. As with many factors influencing absenteeism, effects are not always consistent. Kivimaki et al. [44] in their study on physicians' sickness absence in Finland found that feeling overloaded increased the risk of short 
spells of absence in male physicians and the risk of short and long spells of absence among head nurses and ward sisters. Feeling overloaded, however, did not affect sickness absences among female physicians [44]. In Canada, a study among physicians on the impact of heavy workload on their attitudes and outcomes found that absenteeism increased with increase in workload [19]. Similar trends were observed in studies among nurses and health-care workers [47-49]. Using the RAFAELA ${ }^{\mathrm{mw}}$ (a human resources management system) patient classification system Rauhala and colleagues [50] found that individuals exceeding the optimum workload by $15 \%$ or more had increased risk of sickness absence. This association was the same for both short-term (self-certified) and long-term (physiciancertified) sickness absence [50].

\section{Working conditions}

Effects of working conditions can be related to structural or organizational aspects of work and social aspects. In the United States of America, Trinkoff [51] found that nurses in jobs where they worked with their head or arms in awkward postures were significantly more likely to be absent than those without such demands. In Sweden, Josephson et al. [43] found that nurses dissatisfied with the quality of care provided to patients had higher probability of being on long-term sickness absence. Interference with safety requirements was reported to expose Costa Rican health workers to work-injury absence [52]. Work schedules and terms of contract have been identified as factors that could influence a health worker's presence or absence from work. Ritchie et al. [53] established that part-time staff in the UK had lower rates of absence than full-time staff among most occupational groups, similar to findings from Canada [54-56].

The social context of work is also important. Kivimaki and colleagues [57] found that Finnish health workers that had experienced social exclusion, also seen as a form of bullying, had a high rate of absence. Similarly, bullying and violence from colleagues, patients and visitors was reported to increase absenteeism among nurses in Sweden [43], the USA [58], the Philippines [30], Canada [59], Turkey [60] and radiographers in Hong Kong [61]. Support from colleagues and supervisors may also be influential. In Finland, doctors with poor teamwork were reported to have long sickness absence spells [44], while nurses in primary care were more often absent than those working in teams [62]. The relationship between absenteeism and job satisfaction is inconsistent. Albion [63] reported that high levels of workplace distress among health professionals in Australia were associated with greater duration of absence. Job satisfaction influenced absenteeism in some studies $[64,65]$ while in others there was no apparent relationship [66,67].

\section{Organizational changes}

Changes in organization of health facilities may increase absenteeism depending on how the health workers perceive them $[40,43]$. In Costa Rica, a study was done to assess the effect of hospital management reforms on absenteeism in 29 public hospitals. It was found that introduction of the reforms, which among many other objectives aimed to reduce absenteeism among health workers, actually resulted in an increase in absenteeism [34]. This was attributed to union resistance to the reforms [34].

\section{Individual level factors}

Individuals' personal characteristics influence the absence rate, duration, and reason for absence $[56,68]$.

\section{Marital status}

Marital status has been reported to influence absence from work in different ways in different settings. In Finland, Kivimaki et al. [44] found that male physicians, head nurses and ward sisters who were married were absent less. Absence of female physicians was, however, not influenced by their marital status. In contrast, married Nigerian health workers were reported to be more absent and, of the reasons given, dealing with family problems was common [38]. Borda and Norman [37] noted that family responsibilities increased the probability of female nurses being absent while work-family conflict among Swedish nurses increased the odds of one resigning or being on long-term sickness absence [43].

\section{Age}

In their study in India, Tripathi et al. [26] found that unplanned sickness leave rates were highest among older ward nurses while the highest planned sickness leave rates were among younger operating theatre nurses, with absence mainly attributable to childbirth. In Sweden, nurses older than 50 years had a higher rate of longterm sickness absence [43] with similar findings in Nigeria [38], Canada [56], and Finland [44]. However, increase in absenteeism with increase in age [68] is not always found [55]. Trinkoff et al. [51], while studying effects of physical demands among registered nurses in the USA, established that younger nurses took more sickdays. Such findings are also reported from Nigeria where retrospective analysis of sickness absence records of all hospital employees also found that younger employees and those employed for shorter periods of time had a higher rate and duration of absence [69].

\section{Gender}

Most studies report that women are more often absent than men [68,70-72]. A study among all employees of four National Health Service trusts in Scotland reported 
that women were more likely to have been absent and had higher absenteeism rates across all professions [53]. In Nigeria, a study using self-reported absence and incorporating all hospital staff also established that women were more absent than men [38]. Similar findings have been seen in British Columbia [56], Finland [44], and Sweden [43]. However, Bamgboye and Adeleye [69] in a different study in Nigeria among all hospital employees and Chaudhury and Hammer [21] in their study in Bangladesh among health workers did not find any significant difference in absence rates between men and women.

\section{Level in the hierarchy}

Among health workers, cadres that are higher up in the hierarchy, for example doctors, are said to be less absent compared to other cadres. Kivimaki et al. [44] found that physicians had lower rates of short- and long-term sickness absence compared to the nurses in Finland. In the UK, Ritchie et al. [53] report that auxiliary staff had the highest rates and duration of absence while medical and dental staff had the lowest. Such findings are supported by reports from Nigeria [38,69], Saudi Arabia [73], Thailand [74], Denmark [71] and Switzerland [18].

\section{Individual health status}

The health of an individual is bound to affect how often and how long they are away from their place of work $[16,44,46,56,59,69]$. In Sweden and Norway, health workers with self-reported health complaints had increased risk for sickness absence $[27,75]$. In high-income settings, studies have often focused on musculoskeletal and psychological (stress or burnout) disorders [16,27,43,76]. However, HIV and AIDS infection as a human resources for health problem is mostly unique to Africa [3,12]. HIV and AIDS infection has increased the workload for health workers [77] and led directly to a reduction in numbers and increased sickness absence [78]. Indeed, people that are HIV positive have been reported to be absent from work for up to $50 \%$ of the time in their last year of life [78], added to which is the issue of caring for affected relatives.

\section{Context- or culture-specific reasons}

Although there were not many studies on contextspecific reasons for absenteeism among health workers, a number of studies implied contextual reasons as associated with absence.

\section{Management}

The leadership style used in health facilities can influence the absence trends of health workers. In the Netherlands, managers' leadership effectiveness was inversely related to the number of absencedays and short-term absence of nurses although there was no relationship to long-term absence [79]. However, in work also undertaken in the Netherlands investigating the effects of two leadership styles neither had an effect on absence frequency, although it was proposed that a combination of different styles could lower absence frequency [80].

\section{Cultural expectations}

The expectations of peers and society at large might influence absence patterns among health workers. Although this was not explicitly stated, it is implied that absence 'culture' can influence the absence patterns of health workers [45]. Cultural differences in absenteeism can further be noticed in that some reasons for health worker absenteeism were only found in studies done in LICs. Isah et al. [38] in their study among the entire staff of a hospital in Nigeria identified common causes of absence including: attendance at examinations, social events like marriage and burial, adverse weather conditions, and travel and transportation problems. These are reasons that were not generally reported in studies done in HICs.

\section{Policies}

In Costa Rica, reforms put in place with the objective to reduce absenteeism actually resulted in an increase in absence [34]. The reforms included management contracts with a sick leave policy of not substituting absentee workers intended to reduce overtime costs and activate a peer pressure mechanism to prevent absence. However, this was hard to implement due to union resistance [34]. In Ethiopia, problems arose after legalization of private health care. Here Lindelow and Serneels [7] in a qualitative study reported that health workers were absent from the public sector while attending to patients in the private sector. There were even cases where health workers referred patients from the public sector to their private practice.

\section{Discussion}

This study confirms that there are varied definitions of absenteeism that depend on the context in which the study is conducted, the availability of informative routine data and the factors investigators consider to be most problematic as causes. Even in the same contexts, varying definitions and measures have been used [27,43]. The variability of definitions often proves a challenge when comparing or contrasting research findings, particularly perhaps when trying to understand the apparently inconsistent findings for factors associated with high rates of absenteeism. Drawing generalizable lessons from the body of literature reviewed was also made more difficult by the need to combine literature from countries at all stages of development. However, although our interest was driven by the desire to 
understand absenteeism in LICs the paucity of research from these settings precluded this.

Our review suggests that while investigators may study varied and multiple forms of absenteeism they might consider how these could additionally be characterized based on two key characteristics (Table 1) as: planned/ unplanned and voluntary/involuntary. Using such a classification system may promote the generalizability of research findings and promote exploration of different patterns of absenteeism across different contexts. Classification systems should ideally be easy to use. Further work in this area may justify the inclusion of a further approach to classification to encompass whether the absenteeism episode was officially sanctioned or not (unsanctioned). For example it is possible that some forms of absence might be unplanned, involuntary and unsanctioned. Such a form of absence might result if health workers absent themselves from their expected station to cover for a colleague who is absent. The primary absence thus results in an indirect secondary absence. It seems intuitive that these forms of absence are possible but may be hard to confirm using the methods that predominate in this field to date that rely on self-reported absence or analysis of administrative records.

Despite difficulties with definitions and very limited literature, there are some forms of absenteeism that appear to be of greater concern in LICs, our particular interest. One form of planned absence is attendance at workshops that takes health workers away from their duty stations [22], another clearly the direct impact of health workers' ill-health in Africa resulting from the HIV pandemic. A related problem that may be more prevalent in LICs and that our search may not have captured is presenteeism, the notion of being formally present at work but preoccupied with non-work-related activities [44].

However, it also needs to be noted that health worker absenteeism has often been difficult to measure in both high- and low-resource settings [68,69,81]. Absence records in some form in HICs are often routinely available $[62,79,82]$. Some LICs report having sickness absence records but these often seem to be incomplete or inaccurate $[45,69]$. Even with availability of records, it remains challenging to verify reasons for absence, especially when reasons are self-certified or self-reported, as false reporting and recall bias may limit meaningful interpretation. Interestingly, in one study of nurses in Canada [35], a strong positive correlation and a strong intraclass correlation were observed for self-reported and administratively recorded absence, although a majority of nurses underestimated their absence [35].

The bulk of studies on absenteeism have been in HICs and mostly among nurses $[40,79,83,84]$. The reason that investigators tend to focus on nurses is not clear.
However, we might speculate that this recognizes that numerically nurses are typically the largest single health worker group, that records on nurse absence may be better kept or that investigators feel less comfortable investigating the historically more powerful group of physicians. Amongst nurses, the work tends to coalesce around sickness absence probably linked to the high cost of such absence to patients, governments, taxpayers and even insurance companies $[82,85,86]$. Indeed the design of sickness insurance systems and other forms of social insurance may have a major impact on sickness absence [39]. However, sickness absence may in some cases be an expeditious way of avoiding negative work environments or experiences. It may also be the only way to get time off work to attend to other personal matters [26] (in some settings referred to as 'taking a sickie' [87]). Since it is sometimes difficult to distinguish between genuine sickness and shirking, frequency of absence has been used as an indicator of voluntary absence [23,36] and is predicted by variables such as job commitment. Long duration of absence on the other hand is often felt to be indicative of poor health and is predicted by variables such as burnout [63] and musculoskeletal injuries.

Cadres higher in the hierarchy have been reported to have lower rates of absence [44,53]. They have also been reported to have higher presenteeism than other cadres [44]. As such studies are few, caution is required when interpreting such findings. It is plausible that professional values that require them to be physically present and a lack of people to cover for them when they are away (as they are fewer in number) [88] might reduce absenteeism. However, it is equally plausible that there is poorer collection of information on absenteeism amongst such cadres [38,69]. Indeed in LICs there is often high demand for the services of the few higher level cadres and reports suggest they may be absent from the public sector while providing services in the private sector, especially where policies are relatively permissive $[7,42]$. At all levels of the hierarchy absence may be driven by physical job strain and lack of autonomy and satisfaction $[26,65]$.

Probably due to the complexity of health worker absenteeism, studies on interventions to reduce it are few. A Cochrane review on effects of preventive staffsupport only identified one study that aimed to reduce absenteeism [89]. It showed no significant effect of the intervention [20]. Indeed on occasions policies aimed at controlling absence have resulted in higher absence by undermining employee commitment [39] or producing other unintended effects on management or employee behaviour [34].

\section{Conclusions}

Health worker absence in LICs is likely to exacerbate human resources for health inadequacies and undermine 
demand for, quality of and efficiency of delivery of health services. Despite this it has been infrequently examined by researchers, by far the majority of work having been conducted in HICs. Yet absenteeism may be a barometer for the psychological and physical well-being of health workers and a valuable measure of health systems performance. Further work in LICs might be of more generalizable value if a structured typology of the forms of absenteeism is used. This may help us further understand how different factors related to the work setting, nature of work, individual characteristics, and context influence different forms of absenteeism, thereby providing a rationale for interventions to address it.

\section{Additional file}

Additional file 1: A summary of studies included in the review.

\section{Competing interests}

The authors declare that they have no competing interests.

\section{Authors' contributions}

ME in collaboration with CDC's Health Systems and Human Resources Team, Division of Global HIV/AIDS, developed the research objective for the review. $A B$ carried out the literature searches, retrieved manuscripts and abstracted key data with the help of PM and ME. AB led the efforts to develop the typology and characterize themes emerging from the literature with the help of PM and ME. AB drafted the initial manuscript with help from ME. All authors read and approved the final manuscript.

\section{Acknowledgements}

We are grateful to CDC's Health Systems and Human Resources Team, Division of Global HIV/AIDS, for their support in conducting this work and for comments on the manuscript.

\section{Financial support}

The Centers for Disease Control and Prevention (CDC) sponsored this report through a cooperative agreement with the Association of Schools of Public Health using funding provided by CDC-PEPFAR. This review was additionally supported by Emory University's Kenya Health Workforce Project in partnership with the KEMRI-Wellcome Trust Research Programme. Support provided by The Wellcome Trust through a Core Grant (077092/B/05/F), to Patrick Mbindyo as part of a Strategic Award (084538/Z/07/A) and to Mike English through a Senior Fellowship (097170/Z/11/Z) also made this work possible.

\section{Author details}

${ }^{1}$ Kenya Medical Research Institute -Wellcome Trust Research Programme, Kenyatta National Hospital, Hospital Road, Nairobi 00100, Kenya. ${ }^{2}$ Nuffield Department of Medicine and Department of Paediatrics, University of Oxford, Old Road Campus, Oxford OX3 7BN, UK.

Received: 21 January 2013 Accepted: 1 July 2013

Published: 17 July 2013

\section{References}

1. Chen $L$, et al: Human resources for health: overcoming the crisis. Lancet 2004, 364:1984-1990.

2. Joint Learning Initiative: Human resources for health. Overcoming the crisis. Cambridge, MA: Global Equity Initiative, Harvard University; 2004.

3. Dovlo D: Wastage in the health workforce: some perspectives from African countries. Hum Resour Heal 2005, 3:6.

4. Working together for health. Geneva: World Health Organization; 2006.
5. Kombe G, Galaty D, Gadhia R, Decker C: The human and financial resource requirements for scaling up HIV/AIDS services in Ethiopia. In The Partners for Health Reformplus Project. Bethesda, MD: Abt Associates Inc; 2005.

6. Anand S, Bärnighausen T: Human resources and health outcomes: cross-country econometric study. Lancet 2004, 364:1603-1609.

7. Lindelow M, Serneels P: The performance of health workers in Ethiopia: results from qualitative research. Soc Sci Med 2006, 62:2225-2235.

8. Adano U: The health worker recruitment and deployment process in Kenya: an emergency hiring program. Hum Resour Heal 2008, 6:19.

9. Rakuom C: Nursing human resources in Kenya: case study. Geneva: International Centre for Human Resources in Nursing; 2010.

10. Dambisya YM: A review of non-financial incentives for health worker retention in east and southern Africa.Discussion paper 44. In The Regional Network for Equity in Health in East and Southern Africa. Edited by Loewenson R. 2007.

11. Kober K, Van Damme W: Public sector nurses in Swaziland: can the downturn be reversed? Hum Resour Heal 2006, 4:13.

12. Liese B, Dussault G: The state of the health workforce in sub-Saharan Africa: evidence of crisis and analysis of contributing factors. Washington, DC: World Bank; 2004.

13. Yumkella F: Retention of health care workers in low-resource settings: challenges and responses. In IntraHealth International. ; 2006.

14. Hagopian A, et al: The flight of physicians from West Africa: views of African physicians and implications for policy. Soc Sci Med 2005, 61:1750-1760.

15. Ferrinho $P$, et al: Dual practice in the health sector: review of the evidence. Hum Resour Heal 2004, 2:14.

16. Alexopoulos EC, et al: Knee and low back complaints in professional hospital nurses: occurrence, chronicity, care seeking and absenteeism. Work: A Journal of Prevention Assessment and Rehabilitation 2011, 38:329-335.

17. Steenstra l, et al: Prognostic factors for duration of sick leave due to low-back pain in Dutch health care professionals. J Occup Rehabil 2005, 15:591-605

18. Genevay SP, et al: Work-related characteristics of back and neck pain among employees of a Swiss University Hospital. Joint Bone Spine 2011, 78:392-397.

19. Williams ES, Rondeau KV, Xiao Q, Francescutti LH: Heavy physician workloads: impact on physician attitudes and outcomes. Health Serv Manage Res 2007, 20:261-269.

20. Weir $R$, et al: The efficacy and effectiveness of process consultation in improving staff morale and absenteeism. Medical Care 1997, 35:334-353.

21. Chaudhury N, Hammer JS: Ghost doctors: absenteeism in rural Bangladeshi health facilities. The World Bank Economic Review 2004, 18:423-441.

22. Manzi F, et al: Human resources for health care delivery in Tanzania: a multifaceted problem. Hum Resour Heal 2012, 10:3.

23. Beil-Hildebrand M: Nurse absence-the causes and the consequences. J Nurs Manag 1996, 4:11-17.

24. Becker SG, Oliveira MLC: Study on the absenteeism of nursing professionals in a psychiatric center in Manaus, Brazil. Rev Lat Am Enfermagem 2008, 16:109-114.

25. UNHCO: Establishing incidence of health provider absenteeism in Bushenyi district. Kampala: Uganda National Health Users'/Consumers' Organization; 2010.

26. Tripathi $M$, et al: Absenteeism among nurses in a tertiary care hospital in India. Natl Med J India 2010, 23:143-146.

27. Peterson $U$, et al: Burnout levels and self-rated health prospectively predict future long-term sickness absence: a study among female health professionals. J Occup Environ Med 2011, 53:788-793.

28. Schalk $R$ : The influence of organizational commitment and health on sickness absenteeism: a longitudinal study. J Nurs Manag 2011, 19:596-600.

29. Andreasson H, Ortengren U, Barregard L, Karlsson S: Work-related skin and airway symptoms among Swedish dentists rarely cause sick leave or change of professional career. Acta Odontol Scand 2001, 59:267-272.

30. Fujishiro K, Gee GC, de Castro AB: Associations of workplace aggression with work-related well-being among nurses in the Philippines. Am J Public Health 2011, 101:861-867.

31. Donovan TL, Moore KM, VanDenKerkhof EG: Employee absenteeism based on occupational health visits in an urban tertiary care Canadian hospital. Public Health Nurs 2008, 25:565-575. 
32. Junkes MB, Pessoa VF: Financial expense incurred by medical leaves of health professionals in Rondonia public hospitals, Brazil. Rev Lat Am Enfermagem 2010, 18:406-412.

33. Libet $\mathrm{JM}$, et al: Absenteeism and productivity among mental health employees. Administration and Policy in Mental Health and Mental Health Services Research 2001, 29:41-50.

34. Garcia-Prado A, Chawla M: The impact of hospital management reforms on absenteeism in Costa Rica. Health Policy Plan 2006, 21:91-100.

35. Gaudine A, Gregory C: The accuracy of nurses' estimates of their absenteeism. J Nurs Manag 2010, 18:599-605.

36. Davey MM, Cummings G, Newburn-Cook CV, Lo EA: Predictors of nurse absenteeism in hospitals: a systematic review. J Nurs Manag 2009, 17:312-330.

37. Borda RG, Norman IJ: Testing a model of absence and intent to stay in employment: a study of registered nurses in Malta. Int J Nurs Stud 1997, 34:375-384.

38. Isah EC, Omorogbe VE, Orji O, Oyovwe L: Self-reported absenteeism among hospital workers in Benin city, Nigeria. Ghana Med J 2008, 42:2-7.

39. Johnson CJ, Croghan E, Crawford J: The problem and management of sickness absence in the NHS: considerations for nurse managers. J Nurs Manag 2003, 11:336-342

40. Verhaeghe $\mathrm{R}$, et al: Impact of recurrent changes in the work environment on nurses' psychological well-being and sickness absence. J Adv Nurs 2006, 56:646-656.

41. Allen PT: Size of workforce, morale and absenteeism: a re-examination. $\mathrm{Br} J$ Ind Relat 1982, 20:83-100.

42. Muthama T, Maina T, Mwanje J, Kibua T: Absenteeism of health care providers in Machakos district. Nairobi: Kenya. Report of the Institute of Policy Analysis and Research; 2008.

43. Josephson $M$, et al: The same factors influence job turnover and long spells of sick leave-a 3-year follow-up of Swedish nurses. Eur J Public Health 2008, 18:380-385.

44. Kivimaki $M$, et al: Sickness absence in hospital physicians: 2 year follow up study on determinants. Occup Environ Med 2001, 58:361-366.

45. Nyathi $\mathrm{M}$, Jooste $\mathrm{K}$ : Working conditions that contribute to absenteeism among nurses in a provincial hospital in the Limpopo Province. Curationis 2008, 31:28-37.

46. Plant M: Primary care nurses' attitude to sickness absence: a study. Br J Community Nurs 2003, 8:421-427.

47. Bourbonnais $\mathrm{R}$, Mondor M: Job strain and sickness absence among nurses in the province of Québec. Am J Ind Med 2001, 39:194-202.

48. Bourbonnais R, Vinet A, Vezina M, Gingras S: Certified sick leave as a non-specific morbidity indicator: a case referent study among nurses. $\mathrm{Br} J$ Ind Med 1992, 49:673-678.

49. Verhaeghe $\mathrm{R}$, et al: Job stress among middle-aged health care workers and its relation to sickness absence. Stress Heal 2003, 19:265-274.

50. Rauhala A, et al: What degree of work overload is likely to cause increased sickness absenteeism among nurses? Evidence from the RAFAELA patient classification system. J Adv Nurs 2007, 57:286-295.

51. Trinkoff AM, Storr CL, Lipscomb JA: Physically demanding work and inadequate sleep, pain medication Use, and absenteeism in registered nurses. J Occup Environ Med 2001, 43:355-363.

52. Gimeno D, et al: Association of occupation and safety practices with work-injury absence among public hospital employees in Latin America: a study from Costa Rica. Inj Prev 2007, 13:264-269.

53. Ritchie KA, Macdonald EB, Gilmour WH, Murray KJ: Analysis of sickness absence among employees of four NHS trusts. Occup Environ Med 1999, 56:702-708.

54. Burke RJ, Greenglass ER: Effects of hospital restructuring on full time and part time nursing staff in Ontario. Int J Nurs Stud 2000, 37:163-171.

55. Carosi A, Lightfoot N: Predictors of workplace absenteeism in cancer care workers. Curr Oncol 2009, 16:1-4.

56. Gorman E, Yu S, Alamgir H: When healthcare workers get sick: exploring sickness absenteeism in British Columbia, Canada. Work: A Journal of Prevention, Assessment and Rehabilitation 2010, 35:117-123.

57. Kivimaki M, Elovainio M, Vahtera J: Workplace bullying and sickness absence in hospital staff. Occup Environ Med 2000, 57:656-660.

58. Wilson BL, Diedrich A, Phelps CL, Choi M: Bullies at work: the impact of horizontal hostility in the hospital setting and intent to leave. J Nurs Adm 2011, 41:453-458.

59. Franche R, et al: Examining the impact of worker and workplace factors on prolonged work absences among Canadian nurses. J Occup Environ Med 2011, 53:919-927.
60. Pinar R, Ucmak F: Verbal and physical violence in emergency departments: a survey of nurses in Istanbul, Turkey. J Clin Nurs 2011, 20:510-517.

61. Ng K, et al: Workplace violence-a survey of diagnostic radiographers working in public hospitals in Hong Kong. J Occup Health 2009, 51:355-363.

62. Kivimäki $M$, et al: Sickness absence and the organization of nursing care among hospital nurses. Scand J Work Environ Health 2004, 30:468-476.

63. Albion MJFG, Machin MA, Patrick J: Predicting absenteeism and turnover intentions in the health professions. Australian Health Review: a publication of the Australian Hospital Association 2008, 32:271-281.

64. Siu O-L: Predictors of job satisfaction and absenteeism in two samples of Hong Kong nurses. J Adv Nurs 2002, 40:1-13.

65. Song $R$, et al: Nurses' job satisfaction, absenteeism, and turnover after implementing a special care unit practice model. Res Nurs Health 1997 20:443-452.

66. Matrunola $\mathrm{P}$ : Is there a relationship between job satisfaction and absenteeism? J Adv Nurs 1996, 23:827-834.

67. Pompeii L, Lipscombb H, Dementb J: Predictors of lost time from work among nursing personnel who sought treatment for back pain. Work 2010:285-295.

68. Pines $A$, et al: Rates of sickness absenteeism among employees of a modern hospital: the role of demographic and occupational factors. $\mathrm{Br} J$ Ind Med 1985, 42:326-335.

69. Bamgboye $E$, Adeleye A: Sickness absenteeism in a Nigerian teaching hospital. East Afr Med J 1992, 69:450-455.

70. Al-Shammari SA, Bamgboye EA, Olubuyide I: Sickness absenteeism among employees of a teaching hospital in Saudi Arabia. $J R$ Soc Promot Health 1994, 114:6-10.

71. Kristensen T, Jensen S, Kreiner S, Mikkelsen S: Socioeconomic status and duration and pattern of sickness absence. A 1-year follow-up study of 2331 hospital employees. Biomed Central Public Health 2010, 10:1-11.

72. Rajbhandary S, Basu K: Working conditions of nurses and absenteeism: is there a relationship? An empirical analysis using national survey of the work and health of nurses. Health policy (Amsterdam, Netherlands) 2010, 97:152-159.

73. Bamgboye E, Olubuyide I, Al-Shammari S: The rate of sickness absenteeism among employees at King Khalid University Hospital, Riyadh, Saudi Arabia. East Afr Med J 1993, 70:515-518.

74. Lim A, et al: Influence of work type on sickness absence among personnel in a teaching hospital. J Occup Health 2002, 44:254-263.

75. Eriksen W, Bruusgaard D, Knardahl S: Work factors as predictors of sickness absence: a three month prospective study of nurses' aides. Occup Environ Med 2003, 60:271-278.

76. Anagnostopoulos F, Niakas D: Job burnout, health-related quality of life, and sickness absence in Greek health professionals. Eur Psychol 2010, 15:132-141.

77. Republic of Kenya Ministry of Health: Report on challenges facing the Kenyan health workforce in the Era of HIV/AIDS. Nairobi: Republic of Kenya Ministry of Health; 2004.

78. Tawfik L, Kinoti SN: The impact of HIV/AIDS on the health workforce in developing countries. In World Health Report - Working Together for Health. Geneva: World Health Organization; 2006.

79. Schreuder JAH, et al: Leadership effectiveness and recorded sickness absence among nursing staff: a cross-sectional pilot study. J Nurs Manag 2011, 19:585-595.

80. Boumans NPG, Landeweerd JA: Leadership in the nursing unit: relationships with nurses' well-being. J Adv Nurs 1993, 18:767-775

81. Remsburg R, Armacost KA, Bennett RG: Managing nursing assistant absenteeism. J Nurs Adm 1999, 29:11-14.

82. Swedish Social Insurance: Sickness benefit. Stockholm: Forsakringskassan; 2012. http://www.forsakringskassan.se/wps/wcm/connect/57599e77-65d64326-a15a-0342bc624bf3/Sjukpenning_FK_4086+Fa_enGB.PDF?MOD= AJPERES\&CACHEID=57599e77-65d6-4326-a15a-0342bc624bf3\&useDefault Text $=0$ \&useDefaultDesc $=0$.

83. Unruh L, Joseph L, Strickland M: Nurse absenteeism and workload: negative effect on restraint use, incident reports and mortality. J Adv Nurs 2007, 60:673-681.

84. Kalisch BJ, Tschannen D, Lee $\mathrm{KH}$ : Do staffing levels predict missed nursing care? Int J Qual Health Care 2011, 23:302-308.

85. Lindahl B, OECD: Norway trumps sick leave costs of all industrial countries. Nordic Labour Journal; 2012. http://www.nordiclabourjournal.org/nyheter/ news-2012/article.2012-02-17.2621171737/. 
86. Wallin G: Myths muddle debate on sick leave. Nordic Labour Journal; 2010 http://www.nordiclabourjournal.org/artikler/debat/opinion-2010/mythsmuddle-debate-on-sick-leave/.

87. Wegge J, Schmidt K-H, Parkes C, Van Dick R: 'Taking a sickie': Job satisfaction and job involvement as interactive predictors of absenteeism in a public organization. J Occup Organ Psychol 2007, 80:77-89.

88. Dellve L, Hadzibajramovic E, Ahllborg G Jr: Work attendance among healthcare workers: prevalence, incentives, and long-term consequences for health and performance. Journal ofAdvanced Nursing 2011, 67:1918-1929.

89. Van Wyk BE, Pillay-Van Wyk V: Preventive staff-support interventions for health workers. Cochrane Database Syst Rev 2010, 3:CD003541.

doi:10.1186/1478-4491-11-34

Cite this article as: Belita et al.: Absenteeism amongst health workers developing a typology to support empiric work in low-income countries and characterizing reported associations. Human Resources for Health 2013 11:34

\section{Submit your next manuscript to BioMed Central and take full advantage of:}

- Convenient online submission

- Thorough peer review

- No space constraints or color figure charges

- Immediate publication on acceptance

- Inclusion in PubMed, CAS, Scopus and Google Scholar

- Research which is freely available for redistribution 